\title{
Refractrometic Studies of Binary Mixtures of Flavoured Compounds and Some Hydrocarbons
}

\author{
Neetu Yadav ${ }^{*}$, , Tanvir Arfin ${ }^{b}$ and S.S. Yadava ${ }^{a}$ \\ ${ }^{a}$ Department of Chemistry, DDU Gorakhpur University, Gorakhpur-273009 U.P., India \\ ${ }^{b}$ Chemical Resource Beneficiation (CRB) Research Focus Area, PGM Group, North-West University, Private \\ Bag X6001, Potchefstroom 2520, South Africa
}

\begin{abstract}
Refractive indices have been measured for the binary liquid mixtures of $n$-butylethanoate and 3 methylethanoate with cyclohexane, benzene, 1,4-dimethylbenzene and 1,3,5-trimethylbenzene over the entire composition range at $308.15 \mathrm{~K}$. From the experimental data, the values of deviation in refractive index $(\Delta \mathrm{n})$, molar refraction $(R)$ and deviation in molar refraction $(\Delta R)$ have been determined. The values of $\Delta n$ and $\Delta R$ have been fitted to the Redlich - Kister polynomial equation to determine the standard deviation.
\end{abstract}

Keywords: Refractive index, binary liquid mixtures and molar refraction, density.

\section{INTRODUCTION}

Physical properties of several esters in their binary mixtures have been already reported [1-8]. However, studies in this regard for the determination of refractive indices of the binary mixtures of $n$-butylethanoate and 3-methylbutylethanoate at $308.15 \mathrm{~K}$ are still lacking. Esters are an important class of organic compounds having characteristic fruity odour. They are used as component of perfumes and flavourings. Higher esters have low solubility in water and used as extraction solvents for fine chemicals particularly for certain antibiotics. They are also useful in cosmetics and materials for personal care.

3-methylbutylethanoate is used as solvent for old oil colors, perfuming, shoe polish, metallic paints and in photographic films.

In our laboratory refractive index studies have been made on binary systems of bromoalkanes and cyclohexane and aromatic hydrocarbons. Literature reveals that binary systems of esters and aromatic hydrocarbons have rarely been studied employing refractive index measurements. In view of this, binary systems of flavoured compounds viz.1-butylethanoate and 3-methylbutylethanoate and aromatic hydrocarbons viz. benzene, 1,4-dimethylbenzene and 1,3,5-trimethylbenzene having successive methylation and differing in the polarisablity have been selected in the present investigation. Since cyclohexane has a six membered ring without any $\Pi$-electrons, binary mixtures of both the esters with it are also studied at

*Address correspondence to this author at the Department of Chemistry, DDU Gorakhpur University, Gorakhpur-273009 U.P., India; Tel: +91-09621228143; E-mail: uaneetu@gmail.com experimental temperature in order to have a reference point for composition of unlike molecular interactions.

\section{EXPERIMENTAL}

1-Butylethanoate (merck India, 98\%), 3methylbutylethanoate (Merck India, 99\%), cyclohexane (Merck India, HPLC grade, 99.7\%) benzene (Merck India, 99.7\%), 1,4-dimethylbenzene (Merck, Germany, 99\%)and 1,3,5-trimethylbenzene (Merck, Germany, $98 \%)$ supplied by manufacturers were used. Except HPLC grade cyclohexane, all other chemicals were further purified, before sample preparation, by fractional distillation over one meter long column and only middle fraction of distillates were used.

Binary mixtures were prepared by weight covering whole mole fractions range in a sealed glass vials and component liquids were injected by means of syringe to minimize evaporation losses during sample preparation. Weights were measured employing single pan analytical balance (Model K-15 Deluxe, K. Roy Instruments Pvt. Ltd. Varanasi) with a precision of \pm $0.00001 \times 10^{-3} \mathrm{~kg}$.

Densities of the liquids and their binary mixtures were measured employing stem pyknometer having bulb capacity about $12.0 \times 10^{-6} \mathrm{~m}^{3}$. Liquids in the pyknometer were injected by syringe with about 9.0 $\times 10^{-2} \mathrm{~m}$ long Lumber puncture needle. Pyknometer containing samples was suspended for half an hour in a water thermostat maintain at constant temperature of $308.15 \pm 0.03 \mathrm{~K}$ in order to equilibrate the sample temperature. Densities of liquids and their mixtures were determined with an uncertainty of $\pm 0.0001 \mathrm{kgm}^{-3}$ by taking into account of buoyancy correction [9] as follows: 
$\rho_{\mathrm{t}}{ }^{0}$ (liquid) $=\left(\mathrm{W}^{\prime} / \mathrm{W}\right) \rho_{\mathrm{t}}{ }^{0}$ (water) $+1.2\left[1-\left(\left(\mathrm{W}^{\prime} / \mathrm{W}\right)\right] \mathrm{kgm}^{-3}\right.$

where $\rho_{\mathrm{t}}{ }^{0}$ (liquid) and $\rho_{\mathrm{t}}{ }^{0}$ (water) are the densities of liquid and water respectively at experimental temperature t. W' and $W$ are weights of liquids and water respectively having same volume in pyknometer at temperature $\mathrm{t}^{0} .1 .2 \mathrm{kgm}^{-3}$ is the density of air. Refractive indices of liquids and their binary mixtures were measured with the help of Abbe Refractometer with an uncertainty of \pm 0.0002 (model R-8, MS Advanced Research Instrument Company New Delhi) using white light. Temperature of the sample was kept constant by circulating water from thermostat at constant experimental temperature with the help of tullu pump through the upper and lower prism boxes of the Abbe Refractometer. The diagram and photograph of the refractometer is shown in Figures $\mathbf{1}$ and $\mathbf{2}$ respectively. Measurements of refractive indices were carried out after attainment of constant temperature by the sample. An average of three to four measurements for each sample was taken.

\section{RESULTS AND DISCUSSION}

The experimental values of densities and refractive indices at $308.15 \mathrm{~K}$ for all the four binary mixtures and

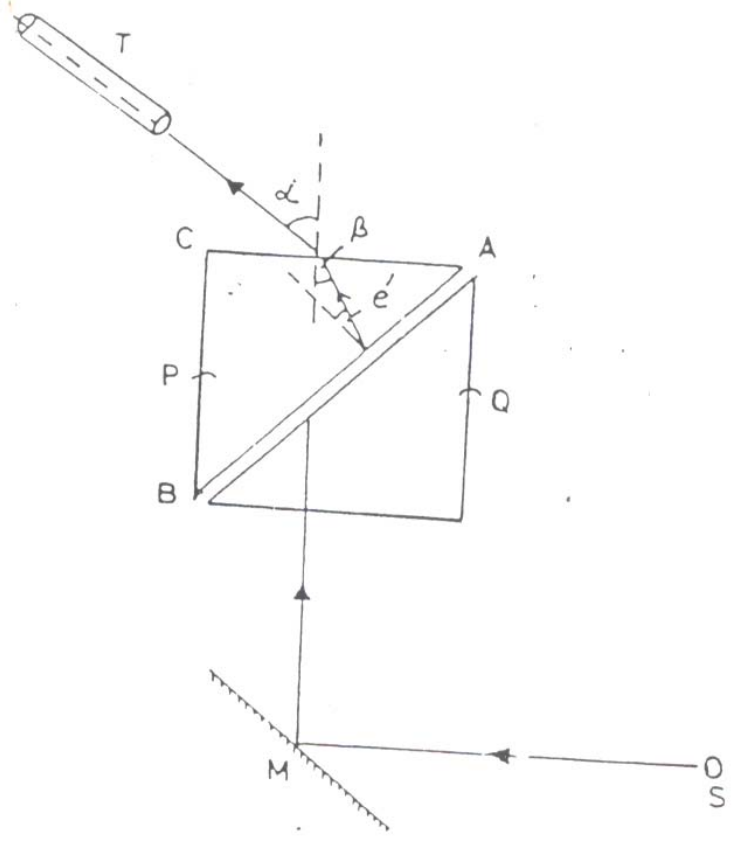

Figure 1: Operating Principle of the Abbe Refractometer.
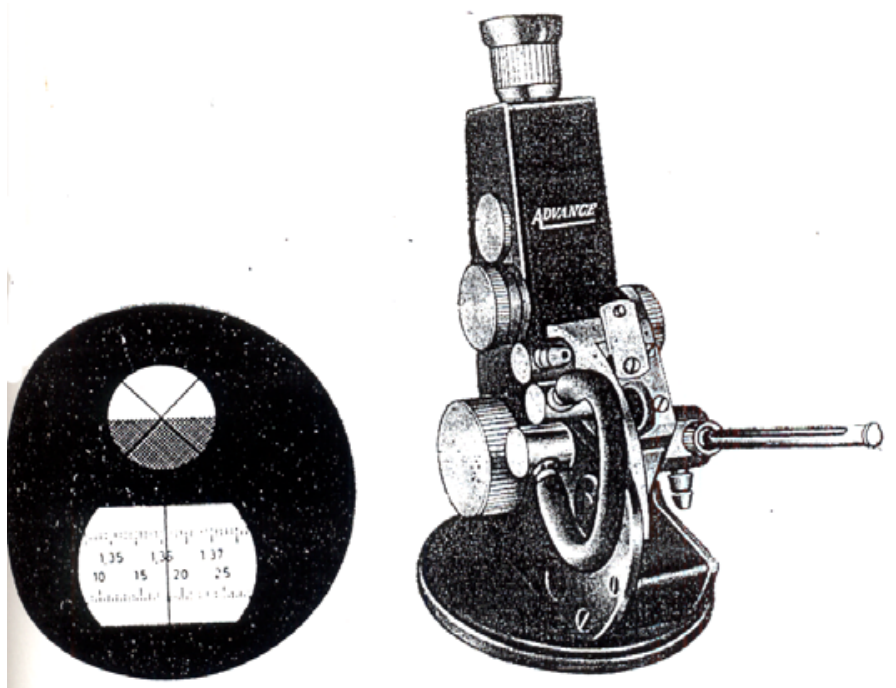

Figure 2: Abbe Refractometer. 
Table 1: Mole Fraction of Hydrocarbons $\left(x_{1}\right)$, Refractive Index ( $\left.n\right)$ and Deviations in Refractive Index ( $\Delta$ ), Molar Refraction (R), Deviations in Molar Refractions $(\Delta R)$ at $308.15 \mathrm{~K}$ for Various Samples of 1-Butylethanoate + Hydrocarbons $\left(x_{1}\right)$ System

\begin{tabular}{|c|c|c|c|c|c|}
\hline S. No. & $\mathbf{x}_{1}$ & $\mathbf{n}$ & $\Delta \mathbf{n}$ & $\begin{array}{c}\mathbf{R x 1 0 ^ { 6 }} \\
\left(\mathrm{m}^{3} \mathrm{~mol}^{-1}\right)\end{array}$ & $\underset{\left(\mathrm{m}^{3} \mathrm{~mol}^{-1}\right)}{\Delta \mathrm{R} \times 10^{6}}$ \\
\hline \multicolumn{6}{|c|}{ 1-Butylethanoate $\left(x_{2}\right)+$ cyclohexane $\left(x_{1}\right)$} \\
\hline 2. & 0.11657 & 1.3902 & -0.0030 & 31.1770 & -0.2424 \\
\hline 3. & 0.20031 & 1.3912 & -0.0045 & 30.8692 & -0.2562 \\
\hline 5. & 0.39690 & 1.3958 & -0.0057 & 30.1264 & -0.2794 \\
\hline 6. & 0.49716 & 1.3984 & -0.0060 & 29.7443 & -0.2737 \\
\hline 7. & 0.60311 & 1.4012 & -0.0063 & 29.3228 & -0.2689 \\
\hline 8. & 0.76467 & 1.4050 & -0.0351 & 29.0649 & -0.1585 \\
\hline \multicolumn{6}{|c|}{ 1-Butylethanoate $\left(\mathrm{x}_{2}\right)+$ Benzene $\left(\mathrm{x}_{1}\right)$} \\
\hline 1. & 0.00000 & 1.3898 & 0.0000 & 31.8078 & 0.0000 \\
\hline 2. & 0.09512 & 1.3938 & -0.0057 & 31.1025 & -0.3390 \\
\hline 3. & 0.19675 & 1.4012 & -0.0088 & 30.5463 & -0.4768 \\
\hline 4. & 0.32022 & 1.4098 & -0.0128 & 29.7921 & -0.6813 \\
\hline 5. & 0.40430 & 1.4182 & -0.0130 & 29.4010 & -0.6667 \\
\hline 6. & 0.48964 & 1.4274 & -0.0125 & 29.0120 & -0.6251 \\
\hline 7. & 0.61107 & 1.4382 & -0.0142 & 28.2540 & -0.7062 \\
\hline 1. & 0.00000 & 1.3898 & 0.0000 & 31.8078 & 0.0000 \\
\hline 2. & 0.10178 & 1.3968 & -0.0030 & 32.0748 & -0.1427 \\
\hline 3. & 0.20346 & 1.4062 & -0.0036 & 32.5014 & -0.1311 \\
\hline 4. & 0.29847 & 1.4152 & -0.0040 & 32.8035 & -0.1583 \\
\hline 5. & 0.39370 & 1.4248 & -0.0037 & 33.3763 & -0.0478 \\
\hline 6. & 0.50142 & 1.4352 & -0.0039 & 33.8304 & -0.0518 \\
\hline 7. & 0.60780 & 1.4462 & -0.0034 & 34.3104 & -0.0306 \\
\hline 8. & 0.70528 & 1.4562 & -0.0030 & 34.7380 & -0.0295 \\
\hline 9. & 0.79968 & 1.4664 & -0.0021 & 35.1948 & -0.0097 \\
\hline 10. & 0.89814 & 1.4768 & -0.0014 & 35.6205 & -0.0083 \\
\hline 11. & 1.00000 & 1.4882 & 0.0000 & 36.0933 & 0.0000 \\
\hline
\end{tabular}


(Table 1). Continued

\begin{tabular}{|c|c|c|c|c|c|}
\hline S. No. & $x_{1}$ & $\mathbf{n}$ & $\Delta \mathbf{n}$ & $\begin{array}{c}\mathbf{R x 1 0} 0^{6} \\
\left(\mathrm{~m}^{3} \mathrm{~mol}^{-1}\right)\end{array}$ & $\begin{array}{c}\Delta \mathbf{R} \times 10^{6} \\
\left(\mathrm{~m}^{3} \mathrm{~mol}^{-1}\right)\end{array}$ \\
\hline \multicolumn{6}{|c|}{ 1-Butylethanoate $\left(x_{2}\right)+1,3,5$-Trimethylbenzene $\left(x_{1}\right)$} \\
\hline 2. & 0.09900 & 1.3978 & -0.0020 & 32.5414 & -0.2002 \\
\hline 3. & 0.20156 & 1.4090 & -0.0012 & 33.5233 & -0.1577 \\
\hline 5. & 0.41012 & 1.4312 & -0.0002 & 35.5071 & -0.1100 \\
\hline 6. & 0.50516 & 1.4410 & -0.0000 & 36.3733 & -0.1045 \\
\hline 7. & 0.61064 & 1.4500 & -0.0031 & 37.0725 & -0.3706 \\
\hline 8. & 0.70100 & 1.4598 & -0.0011 & 38.0492 & -0.1782 \\
\hline
\end{tabular}

Table 2: Mole Fraction of Hydrocarbons ( $\left.x_{1}\right)$, Refractive Index ( $\left.n\right)$, Deviations in Refractive Index ( $\left.\Delta n\right)$, Molar Refractions (R) and Deviations in Molar Refractions $(\Delta R)$ at $308.15 \mathrm{~K}$ for Various Samples of 3Methylbutylethanoate + Hydrocarbons $\left(x_{1}\right)$ System .

\begin{tabular}{|c|c|c|c|c|c|}
\hline S. No. & $\mathbf{x}_{1}$ & $\mathrm{n}$ & $\Delta \mathrm{n}$ & $\begin{array}{c}\mathbf{R} \times 10^{6} \\
\left(\mathrm{~m}^{3} \mathrm{~mol}^{-1}\right)\end{array}$ & $\underset{\left(\mathrm{m}^{3} \mathrm{~mol}^{-1}\right)}{\Delta R} \times 10^{6}$ \\
\hline \multicolumn{6}{|c|}{ 3-Methylbutylethanoate $\left(x_{2}\right)+$ Cyclohexane $\left(x_{1}\right)$} \\
\hline 2. & 0.09460 & 1.3958 & -0.0023 & 35.3181 & -0.5672 \\
\hline 3. & 0.19949 & 1.3968 & -0.0025 & 34.6455 & -0.5147 \\
\hline 5. & 0.39868 & 1.3998 & -0.0046 & 32.9189 & -0.8742 \\
\hline 6. & 0.49719 & 1.4018 & -0.0051 & 32.0806 & -0.9503 \\
\hline 7. & 0.59291 & 1.4032 & -0.0062 & 31.1875 & -1.0469 \\
\hline 8. & 0.69939 & 1.4064 & -0.0057 & 30.6608 & -0.5840 \\
\hline \multicolumn{6}{|c|}{ 3-Methylbutylethanoate $\left(\mathrm{x}_{2}\right)+\operatorname{Benzene}\left(\mathrm{x}_{1}\right)$} \\
\hline 1. & 0.00000 & 1.3942 & 0.0000 & 36.3363 & 0.0000 \\
\hline 2. & 0.09627 & 1.4002 & -0.0034 & 35.3997 & -0.3319 \\
\hline 3. & 0.19928 & 1.4062 & -0.0075 & 34.3266 & -0.7021 \\
\hline 4. & 0.30001 & 1.4132 & -0.0104 & 33.3213 & -0.9510 \\
\hline 5. & 0.39844 & 1.4200 & -0.0136 & 32.2892 & -1.1550 \\
\hline 6. & 0.49437 & 1.4282 & -0.0145 & 31.3291 & -1.2863 \\
\hline 7. & 0.59729 & 1.4384 & -0.0143 & 30.3209 & -1.2766 \\
\hline
\end{tabular}


(Table 2). Continued.

\begin{tabular}{|c|c|c|c|c|c|}
\hline S. No. & $\mathbf{x}_{1}$ & $\mathbf{n}$ & $\Delta \mathbf{n}$ & $\underset{\left(\mathrm{m}^{3} \mathrm{~mol}^{-1}\right)}{R \times 10^{6}}$ & $\begin{array}{c}\Delta \mathrm{R} \times 10^{6} \\
\left(\mathrm{~m}^{3} \mathrm{~mol}^{-1}\right)\end{array}$ \\
\hline \multicolumn{6}{|c|}{ 3-Methylbutylethanoate $\left(x_{2}\right)+1,4$-Dimethybenzene $\left(x_{1}\right)$} \\
\hline 1. & 0.00000 & 1.3942 & 0.0000 & 36.3363 & 0.0000 \\
\hline 2. & 0.90520 & 1.4018 & -0.0013 & 36.3416 & 0.0244 \\
\hline 3. & 0.19034 & 1.4094 & -0.0027 & 36.3102 & 0.0130 \\
\hline 4. & 0.25459 & 1.4184 & -0.0087 & 36.5906 & 0.3073 \\
\hline 5. & 0.39408 & 1.4270 & -0.0128 & 36.2713 & 0.0192 \\
\hline 6. & 0.48939 & 1.4354 & -0.1461 & 36.2243 & -0.0058 \\
\hline 7. & 0.59486 & 1.4458 & -0.0043 & 36.2733 & 0.0694 \\
\hline 8. & 0.69265 & 1.4554 & -0.0039 & 36.2292 & 0.0503 \\
\hline 9. & 0.79706 & 1.4658 & -0.0033 & 36.1743 & 0.0232 \\
\hline 10. & 0.90026 & 1.4768 & -0.0020 & 36.1184 & -0.0039 \\
\hline 11. & 1.00000 & 1.4882 & 0.0000 & 36.0933 & 0.0000 \\
\hline \multicolumn{6}{|c|}{ 3-Methylbutylethanoate $\left(x_{2}\right)+1,3,5$-Trimethylbenzene $\left(x_{1}\right)$} \\
\hline 1. & 0.00000 & 1.3942 & 0.0000 & 36.3633 & 0.0000 \\
\hline 2. & 0.09296 & 1.4028 & -0.0004 & 36.6298 & -0.1293 \\
\hline 3. & 0.20015 & 1.4114 & -0.0002 & 37.2025 & 0.0219 \\
\hline 4. & 0.29585 & 1.4202 & -0.0027 & 37.6596 & 0.0658 \\
\hline 5. & 0.39366 & 1.4300 & -0.0028 & 38.1561 & 0.1205 \\
\hline 6. & 0.48395 & 1.4392 & -0.0019 & 38.6033 & 0.1793 \\
\hline 7. & 0.60501 & 1.4508 & -0.0021 & 39.1323 & 0.1606 \\
\hline 8. & 0.70000 & 1.4602 & -0.0019 & 39.5970 & 0.1881 \\
\hline 9. & 0.79930 & 1.4704 & -0.0013 & 40.0381 & 0.1648 \\
\hline 10. & 0.90516 & 1.4822 & 0.0002 & 40.5593 & 0.1971 \\
\hline 11. & 1.00000 & 1.4912 & 0.0000 & 40.8352 & 0.0000 \\
\hline
\end{tabular}

experimental values of densities for liquids and their mixtures are used to evaluate

$\Delta \mathrm{n}=\mathrm{n}-\mathrm{x}_{1} \mathrm{n}_{1}-\mathrm{x}_{2} \mathrm{n}_{2}$

Where $n$ and $n_{1}, n_{2}$ are refractive indices of the mixtures and the components 1 and 2 are refractive indices of the mixtures and the components 1 and 2 respectively are also recorded in Tables 1 and 2 .

Redlich-Kister equation [11] given below

$\Delta \mathrm{n}=\mathrm{x}_{1} \mathrm{x}_{2}\left[\mathrm{~A}+\mathrm{B}\left(\mathrm{x}_{1}-\mathrm{x}_{2}\right)+\mathrm{C}\left(\mathrm{x}_{1}-\mathrm{x}_{2}\right)^{2}\right]$

Where A, B and C are the coefficients of the equation is generally used by the chemists to analyse thermodynamic data on liquid mixtures. However, Desnoyers and Perron [12] has suggested in agreement with the original statements of Redlich and
Kister, that plot of $Y^{E} / x_{1}\left(1-x_{1}\right)$ is better for this purpose. In the present investigation Redlich - Kister equation was fitted to the evaluated $\Delta n$ values and the coefficients of equation and standard deviation $\sigma(\Delta \mathrm{n})$ for all the systems are recorded in Tables (3-4).

Perusal of Tables 1 and 2 reveals that refractive indices for all the mixtures increases with mole fractions of hydrocarbons. It shows that the order of refractive index for binary mixtures of n-butylethanoate and 3-methylbutylethanoate with hydrocarbons is.

Cyclohexane $<$ benzene $<$ 1,4-dimethylbenzene $<$ 1,3,5-trimethylbenzene

And this order is shown in Figures (3-4).

Variations of deviation in refractive indices, $\Delta \mathrm{n}$ for the mixtures studied with concentrations of 
Table 3: Values of Constants A, B, C and Standard Deviations of Deviation in Refractive Index, $\sigma$ ( $\Delta \mathrm{n}$ ) for Different Binary Systems at $308.15 \mathrm{~K}$

\begin{tabular}{|c|c|c|c|c|c|}
\hline S. No. & System & A & B & C & $\sigma(\Delta \mathrm{n})$ \\
\hline 1. & 1-butylethanoate + Cyclohexane & -0.1270 & 0.0638 & 0.3036 & \pm 0.0221 \\
\hline 3. & $\begin{array}{l}\text { 1-butylethanoate + 1.4- } \\
\text { dimethylbenzene }\end{array}$ & -0.0153 & 0.0093 & 2.0917 & \pm 0.0799 \\
\hline 4. & $\begin{array}{l}\text { 1-butylethanoate }+1.3,5- \\
\text { trimethylbenzene }\end{array}$ & -0.0093 & 0.0237 & -0.3751 & \pm 0.0000 \\
\hline 5. & $\begin{array}{l}\text { 3-methylbutylethanoate + } \\
\text { Cyclohexane }\end{array}$ & 1.5708 & 0.0043 & -0.7431 & \pm 0.3528 \\
\hline 6 & $\begin{array}{l}\text { 3-methylbutylethanoate + } \\
\text { Benzene }\end{array}$ & -0.0335 & -0.1293 & -0.4993 & \pm 0.0238 \\
\hline 7. & $\begin{array}{l}\text { 3-methylbutylethanoate }+1.4- \\
\text { dimethylbenzene }\end{array}$ & -0.1805 & 0.1185 & -0.4605 & \pm 0.0529 \\
\hline
\end{tabular}

Table 4: Values of Constants $A, B$ and $C$ and Standard Deviations of Deviation in Molar Refractions, $\sigma$ ( $\Delta R$ ) for Different Binary Systems at $308.15 \mathrm{~K}$

\begin{tabular}{|c|c|c|c|c|c|}
\hline S. No. & System & A & B & C & $\begin{array}{l}\sigma(\Delta R) \times 10^{6} \\
\left(\mathrm{~m}^{3} \mathrm{~mol}^{-1}\right)\end{array}$ \\
\hline 5. & 1-butylethanoate + Cyclohexane - & 1.2435 & 0.7582 & -0.6949 & \pm 0.0824 \\
\hline 7. & $\begin{array}{l}\text { 1-butylethanoate }+1.4- \\
\text { dimethylbenzene }\end{array}$ & -0.2647 & 0.7471 & 2.8855 & \pm 0.1665 \\
\hline 9. & $\begin{array}{l}\text { 3-methylbutylethanoate + } \\
\text { Cyclohexane }\end{array}$ & -0.0973 & -0.0180 & 0.1265 & \pm 0.8978 \\
\hline 10. & 3-methylbutylethanoate + Benzene & -5.0972 & -1.3610 & 0.0131 & \pm 0.1298 \\
\hline 11. & $\begin{array}{l}\text { 3-methylbutylethanoate + 1.4- } \\
\text { dimethylbenzene }\end{array}$ & 2.9459 & 1.2942 & -0.6813 & \pm 0.6149 \\
\hline
\end{tabular}

hydrocarbons are shown in Figures (5-6). The $\Delta n$ values are negative for all the binary mixtures of ester with all the hydrocarbons.

Experimental $n$ values are used to evaluate molar refraction, $R$ for all the binary mixtures studied by equation:

$R=\left[x_{1} M_{1}+x_{2} M_{2} / \rho\right]\left[\left(n^{2}-1\right) / n^{2}+2\right]$

Where $\mathrm{R}$ is the molar refraction, $\mathrm{x}_{1}$ and $\mathrm{x}_{2}$ are mole fractions of components 1 and $2 M_{1}$ and $M_{2}$ are the molecular weight of component 1 and $2, \rho$ is the density, $\mathrm{n}$ is the refractive index.
$R$ values for all the mixtures also given in Tables 1 and 2 for both the systems with hydrocarbons variations of $\mathrm{R}$ with composition of mixtures are linear for all the binary mixtures. Values of $R$ at equimolar compositions follow the trend similar that of $\Delta \mathrm{n}$ values as given above and shown in Figures $\mathbf{7}$ and $\mathbf{8}$.

Deviation in molar refraction from the linear blending rule $(\Delta \mathrm{R})$ have been defined on mole fraction basis $[13,14]$. Considering molar refraction as isomorphic to the molar volume.However, others $[15,16]$ have defined it on volume fraction basis. In the present investigation $\Delta R$ has been evaluated on volume fraction basis as equation 5 : 


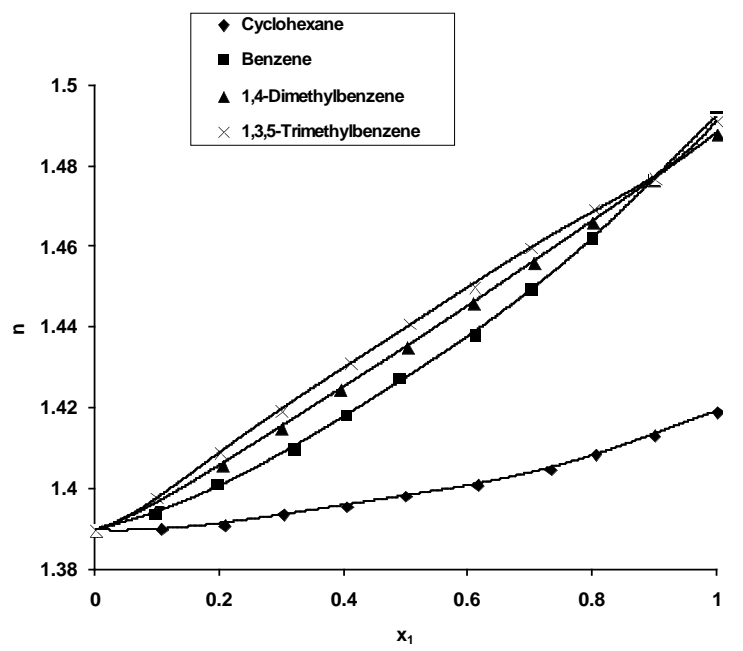

Figure 3: Refractive indices (n) for different binary systems of 1-butylethanoate + hydrocarbons versus mole fractions $\left(x_{1}\right)$ of hydrocarbons at $308.15 \mathrm{~K}$.

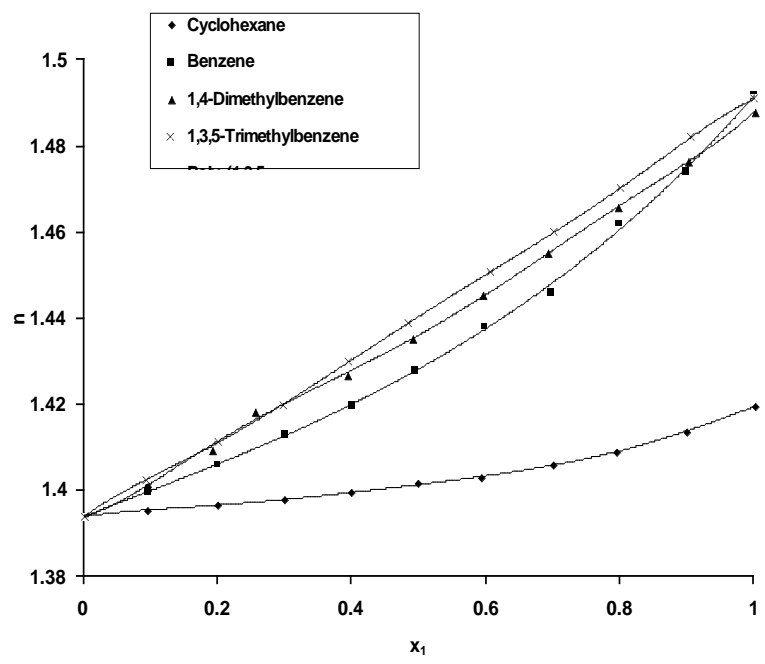

Figure 4: Refractive indices ( $n$ ) for different binary systems of 3-methylbutylethanoate + hydrocarbons versus mole fractions $\left(x_{1}\right)$ of hydrocarbons at $308.15 \mathrm{~K}$.

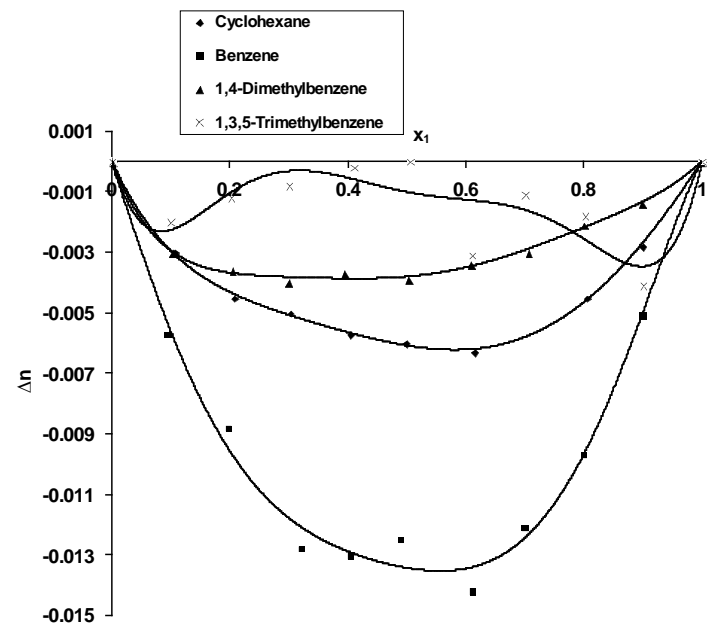

Figure 5: Deviations in Refractive indices ( $n$ ) for different binary systems of 1-butylethanoate + hydrocarbons versus mole fractions $\left(x_{1}\right)$ of hydrocarbons at $308.15 \mathrm{~K}$.

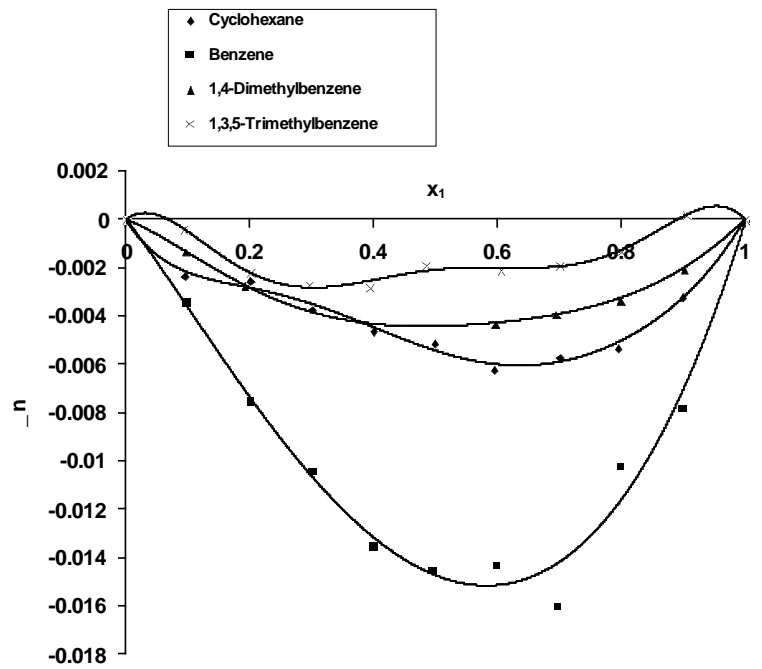

Figure 6: Deviations in refractive indices (n) for different binary systems of 3- methylbutylethanoate + hydrocarbons versus mole fractions $\left(x_{1}\right)$ of hydrocarbons at $308.15 \mathrm{~K}$.

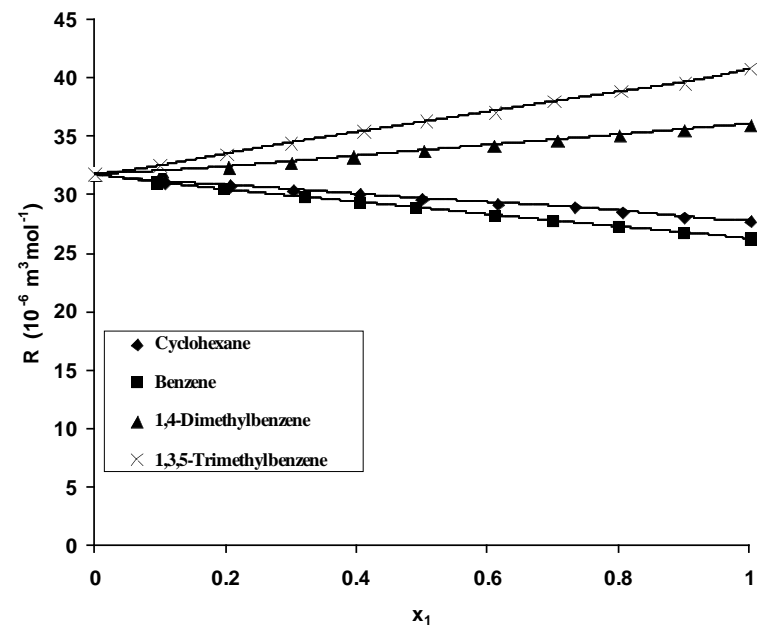

Figure 7: Molar refractions (R) for different binary systems of 1-butylethanoate + hydrocarbons versus mole fractions $\left(x_{1}\right)$ of hydrocarbons at $308.15 \mathrm{~K}$.

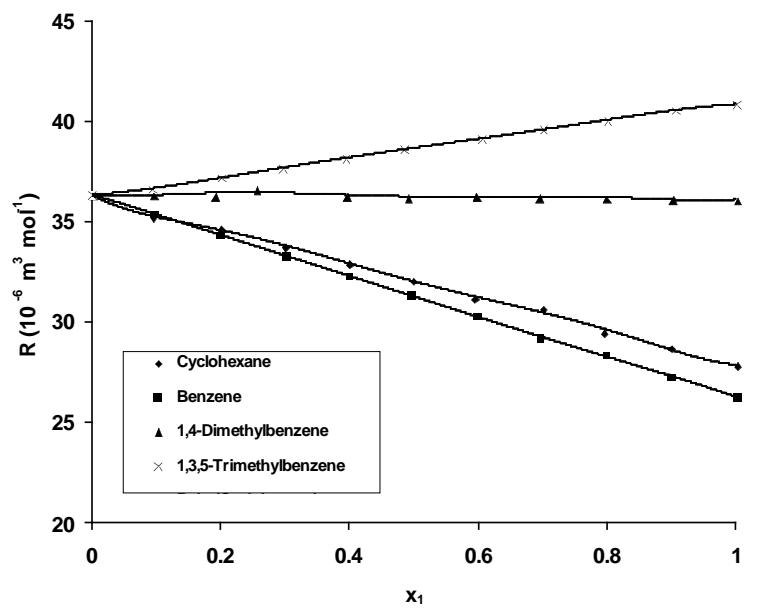

Figure 8: Molar refractions $(\mathrm{R})$ for different binary systems of 3 - methylbutylethanoate + hydrocarbons versus mole fractions $\left(x_{1}\right)$ of hydrocarbons at $308.15 \mathrm{~K}$. 
$\Delta \mathrm{R}=\mathrm{R}-\Phi_{1} \mathrm{R}_{1}-\Phi_{2} \mathrm{R}_{2}$

Where $R_{1}, R_{2}$ are the molar refractions of pure components and $\Phi_{1}$ and $\Phi_{2}$ are their volume fractions in binary mixtures. The $\Delta \mathrm{R}$ values with composition for all the systems at experimental temperature evaluated by equation (4) are recorded in Tables 1 and 2 . Redlich -Kister equation was fitted to the $\Delta \mathrm{R}$ values and the coefficients of the equation together with standard deviation $\sigma(\Delta \mathrm{R})$ for all the systems are recorded in Table 4. Variations of $\Delta \mathrm{R}$ with composition for all the binary systems studied are shown in Figures 9 and 10.

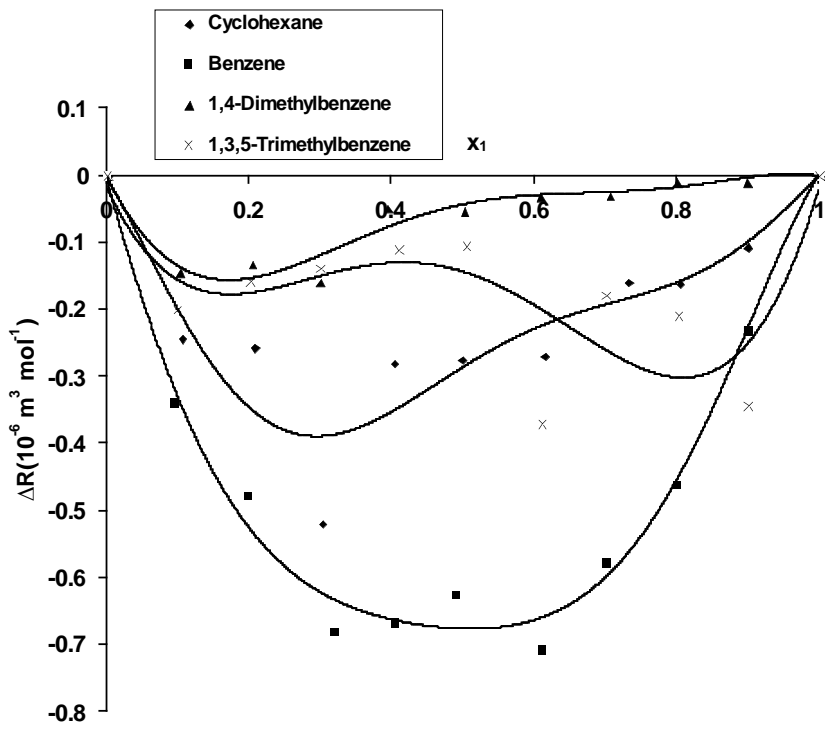

Figure 9: Deviations in Molar refractions $(\Delta R)$ for different binary systems of 1-butylethanoate + hydrocarbons versus mole fractions $\left(x_{1}\right)$ of hydrocarbons at $308.15 \mathrm{~K}$.

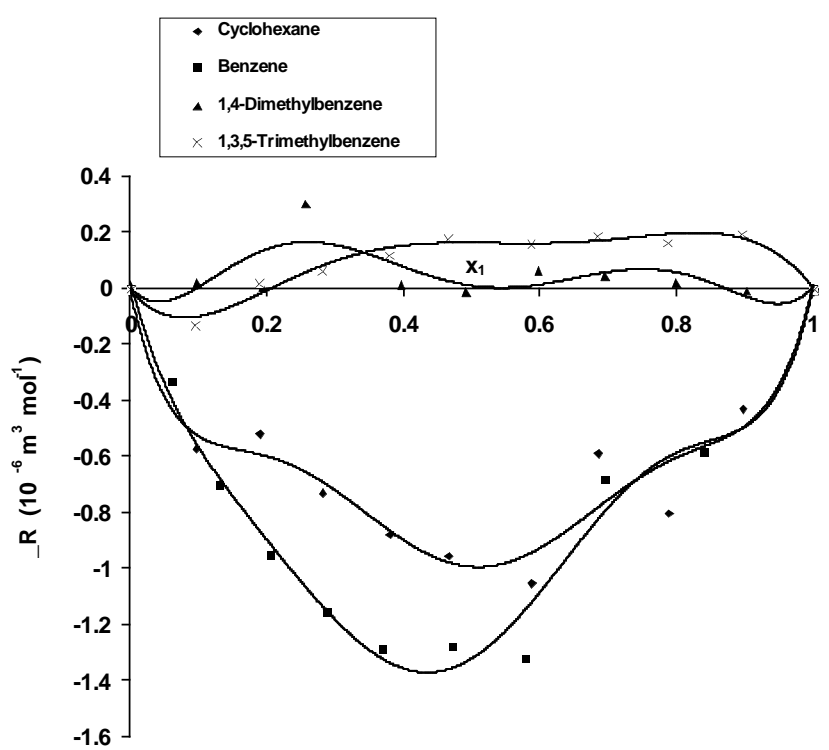

Figure 10: Deviations in molar refractions $(\Delta R)$ for different binary systems of 3-methylbutylethanoate + hydrocarbons versus mole fractions $\left(x_{1}\right)$ of hydrocarbons at $308.15 \mathrm{~K}$.
It is evident from Figures 5 and $\mathbf{6}$ that $\Delta R$ values are negative for binary systems of $n$-butylethanoate with all the hydrocarbons. But for the binary systems of 3methylbutylethanoate $\Delta R$ values are negative for cyclohexane and benzene positive for 1,4dimethylbenzene and 1,3,5-trimethylbenzene.

\section{CONCLUSION}

Refractive index and density of binary mixtures are useful for evaluation of molar refraction. These evaluations give information about molecular interactions between the components of the mixture.

\section{ACKNOWLEDGEMENTS}

The authors are thankful to the Head, Department of Chemistry, D.D.U. Gorakhpur University, Gorakhpur for providing laboratory facilities and to UGC New Delhi for financial assistance.

\section{REFERENCES}

[1] Trenzado JL, Matos JS, Segade L, Carballo E. Densities, Viscosities, and related Properties of some (Methy Ester + Alkane) Binary Mixtures in the Temperature Range from 283.15 to $313.15 \mathrm{~K}$. J Chem Eng Data 2001; 46: 974-83. http://dx.doi.org/10.1021/je0100286

[2] Baragi JG, Aralaguppi MI, Aminabhavi TM. Density, Viscosity, Refractive Index, and Speed of Sound for Binary Mixtures of Anisole with 2-Chloroethanol, 1,4-Dioxane, Tetrachloroethylene, Tetrachloroethane, DMF, DMSO, and Diethyl Oxalate at $(298.15,303.15$, and 308.15) K. J Chem Eng Data 2005; 50: 910-16. http://dx.doi.org/10.1021/je049610v

[3] Diwedi A, Singh M. Densities, viscosities, viscosity deviations and excess thermodynamic properties of binary liquid mixtures of diethyl oxalate and dimethyl malonate with polar and non-polar solvents at $303.15 \mathrm{~K}$. Indian J Chem 2007; 46A: 789-94.

[4] Nikam PS, Kharat SJ. Density and Viscosity Studies of binary Mixtures of $\mathrm{N}, \mathrm{N}$-Dimethylformamide with Toluene and Methy Benzoate at $(298.15,303.15,308.15$, and 313.15) K. J Chem Eng Data 2005; 50: 455-59.

http://dx.doi.org/10.1021/je040012q

[5] Lien PJ, Wu ST, Lee MJ, Lin HM. Excess Molar Enthalpies for Dimethyl Carbonate with $o$-Xylene, $m$-Xylene, $p$-Xylene, Ethylbenzene, or Ethyl Benzoate at $298.15 \mathrm{~K}$ and $10.2 \mathrm{MPa}$. J Chem Eng Data 2003; 48: 632-36. http://dx.doi.org/10.1021/je020181f

[6] Lien PJ, Lin HM, Lee MJ, Venkatesu P. Excess molar enthalpies of diethyl carbonate with $o$-xylene, $m$-xylene, $p$ xylene, ethylbenzene, or ethyl benzoate at $298.15 \mathrm{~K}$. Fluid Phase Equilib 2003; 206: 105-15 http://dx.doi.org/10.1016/S0378-3812(02)00308-4

[7] Garcia B, Alcalde R, Aparicio S, Leal JM. Thermophysical Behavior of Methylbenzoate + n-Alkanes Mixed Solvents. Application of Cubic Equations of State and Viscosity Models. Phys Chem Chem Phys 2002; 4: 5833-40.

[8] Garcia B, Alcalde R, Aparicio S, Leal JM. Thermophysical Behavior of Methylbenzoate $+n$-Alkanes Mixed Solvents. Application of Cubic Equations of State and Viscosity Models. Ind Eng Chem Res 2002; 41: 4399-408. http://dx.doi.org/10.1021/ie020008c 
[9] Lange NA. Hand Book of Chemistry. $10^{\text {th }}$ ed., Mc. Graw - Hill Company, New Yark 1996.

[10] Levitt BP. Findlay's Practical Chemistry. $9^{\text {th }}$ ed., Longman Group Limited, London 1973.

[11] Redlich O, Kister AT. Thermodynamics of Nonelectrolyte Solutions- $x$-y-t Relations in a Binary System. Ind Eng Chem 1948; 40: 341. http://dx.doi.org/10.1021/ie50458a035

[12] Desnoyers JE, Perron G. Treatment of excess thermodynamic quantities for liquid mixtures. J Sol Chem 1997; $26: 749$.

http://dx.doi.org/10.1007/BF02767781

[13] Tojo J, Diaz C. Densities and Refractive Indices for 1-Hexane + o-Xylene, m-Xylene, $+\mathrm{p}$-Xylene, and +Ethylbenzene. J Chem Eng Data 1995; 40: 96-98.

http://dx.doi.org/10.1021/je00017a021
[14] Marchetti AL, Tassi L, Ulrici A, Vaccari G, Sanna G. Refractive indices of binary mixtures of (1,2-dichloroethane + 2-chloroethanol) at various temperatures. $\mathrm{J}$ Chem Thermodyn 1999; 31: 647.

http://dx.doi.org/10.1006/jcht.1998.0475

[15] Aralaguppi MI, Amniabhavi TM, Balundgi RH, Joshi SS Thermodynamic interactions in mixtures of bromoform with hydrocarbons. J Phys Chem 1991; 5299. http://dx.doi.org/10.1021/j100166a070

[16] Amniabhavi TM, Aralaguppi MI, Harogoppad SB, Balundgi $\mathrm{RH}$. Densities, viscosities, refractive indices, and speeds of sound for methyl acetoacetate + aliphatic alcohols (C1-C8). J Chem Eng Data 1993; 38: 31. http://dx.doi.org/10.1021/je00009a008 